\title{
Ultrapassando limites, conjurando a liberdade: revolução e nação na trajetória política de Angelo Bandoni em São Paulo nas duas primeiras décadas do século $\mathrm{XX}$
}

\author{
Kauan Willian dos Santos*
}

Resumo: As trajetórias políticas de militantes ou agentes que percorreram diversos espaços, bem como transitaram em meio de ideologias, classes e pessoas, vêm chamando a atenção de pesquisadores que, em seus estudos, atentam para as nuances e transformações de correntes políticas nos mundos do trabalho, no intuito de compreendê-las de maneira mais complexa. Nesse intuito, o presente artigo percorre a trajetória política do militante Angelo Bandoni no período e localidade de seu ápice ativista (São Paulo entre 1900 e 1920), almejando adentrar as relações entre o próprio desenvolvimento do movimento anarquista e os grupos subalternos e trabalhadores, o contato dessa ideologia com o fenômeno do transnacionalismo e a mudança de perspectivas libertárias frente ao movimento operário, sindicalismo e imperialismo.

Palavras-chave: trajetória política; anarquismo; transnacionalismo.

Abstract: The political trajectories of militants or agents who have crossed several spaces, as well as transited in the midst of ideologies, classes and people, have attracted the attention of researchers who, in their studies, look at the nuances and transformations of political currents in the worlds of work, to understand them in a more complex way. In this sense, this article traces the political trajectory of the militant Angelo Bandoni in the period and locality of his activist apex (São Paulo between 1900 and 1920), aiming to penetrate the relations between the very development of the anarchist movement and the subaltern and working groups, the contact of this ideology with the phenomenon of transnationalism and the change of libertarian perspectives before the labor movement, syndicalism and imperialism.

Keywords: political trajectories; anarchism; transnationalism.

* Mestre em História pela Universidade Federal de São Paulo (UNIFESP). 


\section{Introdução: Angelo Bandoni, subvertendo a ordem}

Angelo Bandoni nasceu no dia 2 de julho de 1868 na cidade de Bastia, na ilha de Córsega, território da França. Seus pais eram italianos, província de Livorno, região da Toscana, e provavelmente precisaram emigrar de sua cidade devido às condições materiais e pela vida conturbada que acometia a maioria da população nesse período. ${ }^{1}$ Não temos certeza se eram trabalhadores rurais, urbanos ou, o que é mais provável, os dois, uma vez que era comum trabalhadores agrícolas, ainda em maioria, mudarem para as áreas urbanas em crescimento naquele momento em centros industriais como haviam morado. ${ }^{2} \mathrm{Em}$ momentos de crises de produção ou escassez na lavoura, procurando novos tipos de empregos e ocupações, esses trabalhadores, antes mesmo da grande imigração em massa para outros continentes, já podiam se deslocar dentro da Europa, processo que foi possibilitado devido à evolução dos transportes, principalmente as ferrovias e os trens a vapor. ${ }^{3}$

Muitos personagens inseridos nesse contexto sofriam uma grande insegurança estrutural, ou seja, com péssimos salários e instabilidade em seus empregos, comumente ficavam sem meios estáveis básicos de subsistência. ${ }^{4}$ Procurando melhores condições de vida, homens e mulheres tentavam circular em diversos territórios que ouviam falar ou liam na imprensa, em expansão também naquele período com as transformações da tipografia..$^{5}$ É nesse contexto que, com 18 anos, Bandoni, ainda próximo da comunidade de origem italiana de sua cidade, viaja, com seu pai e irmão, para La Spezia, uma das províncias da Ligúria. $\mathrm{Na}$ Itália, se tornou um indivíduo procurado pelas autoridades como criminoso. $\mathrm{Na}$ realidade, não temos informações em que momento da sua vida o personagem se envolve com atividades tidas como ilegais, mas é em Lucca, no ano de 1887, cidade da região da Toscana, que Bandoni foi detido a primeira vez pelo crime de roubo e falsificação de bilhetes de trem. ${ }^{6}$

A opção para a realização de tais atos ou para a aproximação de grupos julgados como criminosos era verossímil nesse contexto. Apesar da pressão exercida pelo sistema político e econômico, eram auxiliados pelas transformações industriais, como as ferrovias e a imprensa, garantindo rotas criminosas translocais,

1 A maioria das informações sobre Angelo Bandoni referentes ao período de seu nascimento até a vinda ao Brasil foram sistematizadas pelo historiador Luigi Biondi a partir dos documentos do Archivio Centrale dello Stato di Roma na sessão Cassellario Politico Centrale (CPC) e algumas informações das prefeituras locais de alguns pontos da Itália, principalmente na região da Toscana. Ver BIONDI, Luigi. "La stampa anarchica in Brasile: 1904-1915". (Tese di Laurea. Universitá di Studi di Roma, 1994).

2 Carlo Romani ao realizar a biografia de Oreste Ristori, personagem com muitas semelhanças ao de Angelo Bandoni, afirma que boa parte daqueles trabalhadores na região da Toscana poderiam ser os bracciantis, que alugavam sua força de trabalho em diversas fazendas. $O$ autor também aponta crises que fizeram esses trabalhadores não qualificados a procurarem novos empregos nas áreas urbanas. Sobre o assunto, cf. ROMANI, Carlo. "Oreste Ristori: Uma aventura anarquista". (Dissertação de mestrado em História, Universidade Estadual de Campinas, 1998), p. 10-15.

3 Sobre a evolução dos transportes e as fases industriais, cf. HOBSBAWM, Eric. Era das revoluções: Europa 1789-1848. Rio de Janeiro: Paz e Terra, 1977.

4 Para Mike Savage "na sociedade capitalista, a retirada dos meios de subsistência das mãos dos trabalhadores significa constrangê-los a acharem estratégias para lidar com a aguda incerteza da vida diária, que deriva de seu estado de impossibilidade de reprodução autônoma e sem o apelo a outras agências." SAVAGE, Mike. "Classe e História do Trabalho." In: BATALHA, Claudio; FORTES, Alexandre; SILVA, Fernando Teixeira da. Culturas de classe: Identidade e diversidade na formação do operariado. São Paulo: Editora da Unicamp, 2005, p. 33.

5 Sobre as transformações da tipografia e imprensa, cf. ANDERSON, Benedict. Comunidades Imaginadas: reflexões sobre a origem e a difusão do nacionalismo. São Paulo: Companhia das Letras, 2008.

6 BIONDI. "La stampa anarchica in Brasile." p. 73-75. 
transnacionais e a cooperação entre diversos grupos e indivíduos que cresciam potencialmente, fazendo com que fossem passadas informações sobre como fugir da repressão policial ou lugares mais favoráveis para tais ações. Na concepção do historiador Diego Galeano, se alguns optavam por lutar contra essas opressões de maneira direta, outros aproveitavam "as múltiplas rotas criminais que esse status quo tornara possível". ? Longe de serem delinquentes, como julgavam as autoridades do período, podemos encaixá-los, como estamos tencionando, dentro do mesmo sistema dos personagens que eram coagidos à mercantilização de sua força de trabalho ao se depararem com a instabilidade de suas vidas, mas, ao invés de optarem por vender ou alugar essa força, tentavam conseguir meios de manter sua subsistência longe das longas jornadas das fábricas e fazendas. Nesse sentido, para Marcel van der Linden, os trabalhadores assalariados não eram os únicos a sofrerem os males da expansão capitalista. ${ }^{8}$ Na própria formação desse sistema econômico e o enriquecimento de uma pequena classe proprietária, houve a necessidade da expropriação e colonialismo de diversas regiões, produzindo escravos, gerando também miséria nesses locais. Do mesmo modo, a grande demanda excedente de pessoas para as nascentes fábricas, aumentando a necessidade de trabalhadores não qualificados - prostitutas, meeiros, pequenos artesãos, moradores de rua e outros que, na verdade, formavam um grande grupo marginalizado e podem combinar vários tipos de funções para sua sobrevivência, figurando o que se pode chamar de trabalhadores subalternos. ${ }^{9}$

Assim, nas rotas criminosas, mas ainda compartilhando muitas das mesmas opressões de classe e consequentemente de ideários e formas de resistência, Bandoni pode ter ouvido falar a primeira vez sobre anarquismo ou algo bem próximo a essa ideologia. Após o colapso da Primeira Internacional, ambiente que garantiu ao anarquismo ser expandido dentro da classe trabalhadora, essa ideologia sofreu uma flexibilização e precisou apostar em outros ambientes de resistência além dos sindicais. ${ }^{10}$ Nos lugares com a falta desses e com intensa repressão, optavam ou eram condicionados majoritariamente nas suas redes militantes clandestinas, esparsas e não orgânicas."1

A estratégia anarquista que se desenvolveu nesse seio era chamada de antiorganizacionista que, pela sua distância dos ambientes mais programáticos, desenvolveu um ideário antissindicalista, contra qualquer tentativa de reformismo. Esses ativistas constituíram o anarquismo em meio aos movimentos insurrecionais que usavam como tática principal a "propaganda pelo fato", ${ }^{12}$ que era encarnada

7 GALEANO, Diego. "Criminosos viajantes, vigilantes modernos. Circulações policiais entre Rio de Janeiro e Buenos Aires, 1890-1930". (Tese de doutorado em História, Universidade Federal do Rio de Janeiro, 2012), p. 39.

8 Para adentrar as relações entre trabalhadores, força de trabalho e capital nas interpretações marxistas ver LINDEN, Marcel van der. "Proletariado: conceitos e polêmicas." Revista Outubro, v. 21, n. 1, p. 1-25, fev. 2013.

9 O conceito de trabalhadores subalternos pode ser aprofundado e verificado em LINDEN, Marcel van der. Trabalhadores do Mundo: Ensaios para uma história global do trabalho. Campinas: Editora da Unicamp, 2013.

10 Para adentrar a formação e desenvolvimento do anarquismo bem como suas correntes e estratégias, cf. SCHMIDT, Michael; VAN DER WALT, Lucien. Black Flame: the revolutionary class politics of anarchism and syndicalism. Oakland: Ak Press, 2009.

11 ROMANI. "Oreste Ristori", p. 15.

12 Uma ampla disseminação da propaganda pelo fato e das ações violentas podem ser entendidas ao observar o andamento do congresso em questão, que tinha representantes de várias partes do globo, além de apresentar diversos tipos de ações propagandistas ou violentas. Alexandre Samis nos informa que o "Congresso Anarquista de Londres (de 14 a 20 de julho de 1881), no ano seguinte à fórmula defendida por Kropotkin, com representações da América, Alemanha, Inglaterra, Bélgica, Egito, Espanha, França, Holanda, Itália, Rússia, Sérvia, Suíça e Turquia, aprovaria, na sua segunda sessão, como tática para se alcançar a Revolução Social, a "propaganda pelo fato" e a ação ilegal, em oposição às disputas parlamentares e a apatia diante dos avanços da burguesia." SAMIS, Alexandre. "Minha pátria é o mundo inteiro: Neno Vasco, anarquismo e as estratégias sindicais nas primeiras décadas do século XX". (Tese de 
pela própria ação dos movimentos, acreditando que práticas de boicote ou o uso da violência ocasionariam uma possível ação revolucionária. ${ }^{13}$

Por essa estratégia, os pensamentos anarquistas circulavam em grupos criminosos ou violentos que, muitas vezes, misturavam o ideário de revolução violenta do anarquismo com suas práticas de expropriação e roubo, por vezes individualistas. Havia a possibilidade também de grupos de livre pensamento e anticlericais disseminarem panfletos, jornais ou livros anarquistas, ou mesmo acontecia de personagens que leram ou obtiveram contato pessoal com algum autor ou militante anarquista influenciarem tais círculos. ${ }^{14}$ Devemos considerar também que as lutas de unificação italiana, principalmente as vertentes radicais como o republicanismo mazziniano que difundia o associativismo de classe, o insurrecionalismo popular e a solidariedade internacional também abriram brechas para o florescimento do anarquismo nos lugares onde Bandoni estava passando nesse momento. ${ }^{15}$

No entanto, nessa fase de sua vida, para Luigi Biondi, primeiro historiador que procurou vestígios sobre o personagem com mais profundidade, as informações encontradas são bem controversas. Para o autor, de acordo com a polícia italiana, Bandoni se tornou anarquista depois de ir para a Argentina com seus pais em 1893; no entanto, de acordo com a prefeitura de Lucca, Bandoni teria sido nesse momento um fugitivo na Argélia escapando das acusações de roubo na Itália. Além disso, na Argélia, parece ter sido condenado em 1890, novamente por roubo e, antes do termo de sentença, foi repatriado para La Spezia. O autor ainda acrescenta que, segundo outras fontes policiais, Bandoni e seu pai, em 1893, foi de La Spezia para o Brasil, e não para a Argentina, e na América é que se tornou anarquista, voltando para a Itália, onde foi detido e cumpriu sentença até 1900. ${ }^{16}$ De toda maneira, a própria dificuldade em encontrar vestígios e ter certeza dos passos do personagem, indica que sua vida estava totalmente à margem da sociedade ou, pelo menos, da vigilância e do sistema que setores dominantes dessa sociedade almejavam criar.

A próxima informação mais certa é que, libertado da prisão em março de 1900, em vez de ser vigiado por um ano em liberdade como foi atribuído em sua sentença, preferiu viajar para o Brasil, em São Paulo, lugar onde muitos já estavam se deslocando tentando uma nova vida que lhes fora prometida. ${ }^{17} \mathrm{Nas}$ duas décadas seguintes, Angelo Bandoni se tornou um dos maiores responsáveis pelo desenvolvimento do anarquismo, de sua inserção entre os trabalhadores e grupos subalternos, de várias iniciativas educativas para uma parcela da população empobrecida, de estar envolvido em inúmeras greves e boicotes e de criar jornais bastante lidos e difundidos nos bairros operários. É sobre essa trajetória política que nos atentaremos a seguir.

doutorado em História, Universidade Federal Fluminense, 2009), p. 67.

13 SCHMIDT; VAN DER WALT. Black Flame, p. 129.

14 ROMANI. "Oreste Ristori", p. 14-16.

15 Sobre as conexões entre republicanismo mazziniano e anarquismo na rede étnica italiana, cf. GODOY, Clayton. "Ação Direta: Transnacionalismo, visibilidade e latência na formação do movimento anarquista em São Paulo". (Tese de doutorado em Sociologia, Universidade de São Paulo, 2013).

16 BIONDI. "La stampa anarchica in Brasile", p. $72-75$.

17 Sobre o assunto, cf. TRENTO, Angelo. Do outro lado do Atlântico: um século de imigração italiana no Brasil. São Paulo: Nobel, 1988, p. 19-27. 


\section{Em São Paulo: em busca da revolução, os italianos ouvem mais}

Naqueles dias, o porto de Santos já tinha recebido seus milhares de imigrantes, processo que ocorria em vários pontos do Brasil. ${ }^{18}$ Os recém-chegados aguardavam a liberação dos seus documentos e depois seguiam caminho nas locomotivas da São Paulo Railway que ligava Santos a Jundiaí. Homens e mulheres sem destino definido terminavam na Hospedaria de Imigrantes, junto à estação do Brás, lugar onde eram alocados para trabalharem nas cidades do interior como Araraquara, Campinas, Piracicaba, São José do Rio Preto e outras ou para ficarem na capital, onde muitos começavam suas atividades no comércio ou nas fábricas. ${ }^{19} \mathrm{O}$ avanço industrial e a grande recepção de pessoas nesses ambientes resultavam no rápido crescimento dos centros urbanos. Tal processo, que ocasionava a construção de bairros operários e das habitações populares, próximos às áreas férreas como Água Branca, Barra Funda, Brás, Bom Retiro e Luz ou próximos aos rios, como Pari, Belenzinho, Penha e Mooca, foi marcado por uma clara distinção social em relação a outras regiões de moradia, como Higienópolis, no qual se concentrava a população com maiores rendimentos, que apresentava melhores instalações, inclusive de saneamento básico. ${ }^{20}$

Não sabemos em qual desses bairros Angelo Bandoni se alocou logo quando chegou na cidade, mas podemos afirmar, com muita chance, que foi em algum desses bairros operários. De todo modo, no início de 1902, Bandoni já dirigia o jornal Germinal no qual mostrava sua clara orientação anarquista. As impressões do periódico eram feitas pela tipografia localizada na Rua Bresser $n .^{\circ} 200$, no bairro do Brás, onde era também a redação do jornal e possivelmente onde o personagem se instalava. Também não temos informações claras de como Bandoni conseguiu dinheiro tão rápido para ter máquinas tipográficas, mas tudo indica que sua rápida adaptação se deve a sua própria orientação política e ideológica. Nesse período, grupos ou militantes anarquistas faziam questão de receber outros ativistas ou simpatizantes que desejavam entrar nas suas fileiras políticas e conseguiam lugares para moradia, bem como ensinavam algum ofício para trabalharem nos momentos que não estavam em atividade política. ${ }^{21}$

Os anarquistas, ainda poucos, já tentavam sua inserção na cidade e na classe trabalhadora há algum tempo, desde 1892 pelo menos. Galileo Botti tinha lançado o periódico Gli Schiavi Biachi nesse ano, Felice Vezzani havia fundado o periódico L'asino Humano e o Centro Socialista Internazionale de São Paulo. Este último, iniciado no ano 1893, em um salão na Rua Líbero Badaró n. ${ }^{\circ} 110$, no bairro da Sé, reuniu, em seus primeiros encontros, socialistas e anarquistas na tentativa de unir esforços para discutirem melhores táticas e estratégias para o florescimento de suas ideologias e para mobilizarem a população. ${ }^{22}$ É bem provável que Bandoni, conhecendo antes ou não o anarquismo, mas com possíveis contatos dentro de

18 O historiador Uassyr de Siqueira mostra que "pouco após a abolição, em 1892, foram 92 mil os imigrantes que chegaram no estado, número que, inserido entre os anos de 1880 e 1920, resultou em 1,5 milhões." SIQUEIRA, Uassyr de. "Entre sindicatos, clubes e botequins: identidades, associações e lazer dos trabalhadores paulistanos (1890-1920)". (Tese de doutorado em História, Universidade Estadual de Campinas, 2008), p. 11.

19 SAMIS. "Minha pátria é o mundo inteiro.", p. 86.

20 GODOY. "Ação Direta", p. 73.

21 SAMIS. "Minha pátria é o mundo inteiro.", p. 87-90.

22 Cf. GODOY. "Ação Direta.", p. 85-102. 
sua experiência, tivesse lido algum desses periódicos e procurado alguns de seus personagens ou mesmo comparecido em uma de suas reuniões, a fim de somar seus esforços na luta libertária. Assim, se não havia feito parte ainda de um grupo anarquista, sua formação militante foi bem rápida já que, em 1900, no mesmo ano que chegou, é citado como um colaborador do periódico Palestra Social, escrevendo muitas de suas colunas. Em 1901 anunciam sua primeira conferência, intitulada "Ragione e Amore". ${ }^{23}$ Alguns meses depois, o então ativista lança um opúsculo chamado La Protesta Humana, que é assinado pelo Circolo Educativo Libertario Germinal de São Paulo, grupo criado pelo personagem. No ano de 1902, o grupo lança o periódico Germinal, com Angelo Bandoni também seu diretor e principal redator, no qual definia dentre seus objetivos "lembrar constantemente os desejosos e oprimidos de suas condições degradantes de vida, as causas geradoras da pobreza e da vileza proletária, ligar e manter vivo o espírito de intolerância e rebelião"..24

Angelo Badoni que, pelos vestígios, parece ter sido um homem bastante atento ao seu redor e observador, conhecia bem o estágio de desenvolvimento político do anarquismo no período, uma vez que também cita no primeiro número de seu periódico que havia cerca de "quatrocentos anarquistas" 25 na cidade. Levando isso em consideração, o militante almejava repensar a maneira que os ideais libertários estavam sendo tratados e desenvolvidos. A geração anterior de ativistas conseguiu chamar atenção dos seus opositores e estabelecer conexões com o movimento operário e anarquista internacional, mas parecia que ainda não estavam muito próximos dos problemas locais da população. ${ }^{26} \mathrm{Era}$ a hora de ouvir essas pessoas e instigá-los a partir de seus problemas e não de um programa prédefinido. De fato, Bandoni fazia parte da geração de anarquistas que almejavam agir de acordo com a vontade e necessidade concreta dessas pessoas. Não é em vão que no mesmo ano, ainda em 1902, O Amigo do Povo, primeiro periódico anarquista de língua portuguesa, era lançado pelos militantes Neno Vasco, Benjamin Mota e Edgard Leuenroth, no qual advertiam:

Devemos favorecer todas as lutas por liberdades parciais: na luta aprende-se a lutar e quem começa a saborear um pouco de liberdade acaba por querê-la toda. Estejamos sempre com o povo, procuremos ao menos que pretenda alguma coisa e que esse pouco o que queira, o queira conquistar por si mesmo. (...) Contra o governo, que tem exércitos e policiais, não se faz guerra de argumentos que não convencem: a luta é toda física, material. ${ }^{27}$

O grupo de militantes em questão discordava da estratégia política de Bandoni de não se associar com as entidades de trabalhadores mais pragmáticas, como os sindicatos, e apostam no organizacionismo, acreditando que uma

23 BIONDI. "La stampa anatchica in Brasile", p. 74.

24 Germinal, São Paulo, 10 fev. 1902, p. 1. Tradução nossa. Citação original: "Difficile missione é la nostra... Richiamare costantemente l'attenzione dei desiderati e degli opressi sulle loro avvilenti condizioni di vita, sulle cause generatrici della miseria e dell'abbiezione proletaria, accendere e mantenere vivo lo spirito d'insofferenza e di ribellione."

25 Cf. Germinal, São Paulo, 10 fev. 1902, p. 1. Tradução nossa. Citação original: "Gettare le basi d'un periodico di parte nostra, raggruzzolare tanto denaro per farlo uscire regorlamente duo voltre o tre, non è cosa, in vero, molto penosa in S. Paulo, dove - stando statistica delle grandi evenienze - vi debbono essere oltre a quatrocentro anarchici... Questione maledetta si é poi quella poter continuamente la publicazione (...)."

26 Clayton Godoy separa a primeira geração de anarquistas entre 1892 e 1897 e faz as afirmações feitas em questão. GODOY. "Ação Direta.", p. 80-131.

27 O Amigo do Povo, São Paulo, 7 jun. 1902, p. 2. 
luta pela melhoria da vida material e a revolução estavam em consonância. ${ }^{28}$ Bandoni, que recusava lutar dentro de entidades que poderiam gerar um tipo de autoridade ao se cristalizarem, concordava, ao mesmo tempo, que o anarquismo deveria andar ao lado dos trabalhadores e oprimidos e não acima, deveriam criar espaços e medidas que aproximariam esses personagens, por isso, vários grupos anarquistas que proliferavam no momento começaram a agir como células. Eram os grupos de afinidade que assumiam, cada um, alguma função e se complementavam. O grupo em torno do O Amigo do Povo panfletava nos sindicatos e, com o Grupo Nuova Civilitá, criavam centros de estudos sociais e de biblioteca; o Grupo Filodramático criava peças teatrais, o grupo La propaganda publicava livros e opúsculos e o Germinal, de Bandoni, fomentava a criação de escolas e conferências. ${ }^{29}$

A partir disso, parecia, para Bandoni, que as ações violentas como roubos e assassinatos, típicas do insurrecionalismo que ele mesmo pregava, não faziam mais sentido. ${ }^{30}$ Os seus ideais ainda tinham como perspectiva uma insurreição violenta e uma ruptura definitiva com o sistema então vigente, mas era preciso acender essa fagulha da liberdade de outra forma. Por isso, o militante se envolveu com a educação para os trabalhadores e oprimidos, se tornando um dos maiores conferencistas dos espaços operários do período. Pelo que os jornais deixam a entender, Bandoni tinha uma ótima oratória e seus discursos prendiam a atenção de seus ouvintes. ${ }^{31} \mathrm{O}$ militante, com certeza, havia lido e concordado com os textos e debates anarquistas que consideravam a dominação ideológica e cultural, além da material, um dos pilares da desigualdade. ${ }^{32}$ Nessa empreitada, apesar de ajudar e trabalhar com ativistas de estratégias diversas, logo conheceu companheiros que tinham uma trajetória bem parecida e concordavam com a maioria de seus métodos; eram Oreste Ristori, Alessandro Cerchiai e Gigi Damiani. Tais personagens começaram a trabalhar no periódico La Battaglia, lançado em 1904, que conseguiu uma tiragem de 5.000 exemplares, número surpreendente para qualquer periódico do período, ultrapassando, inclusive, o número de impressões de muitos jornais da chamada grande imprensa. ${ }^{33}$

O periódico La Battaglia noticiava os abusos dos chefes das fábricas e fazendas, marcava reuniões e palestras, noticiava pequenas greves, incentivava o boicote às fábricas e fugas nas fazendas, criticava a classe política sistematicamente e ainda disseminava sua resolução para esses problemas que, para eles, era o fim do sistema político e econômico pelo levante dos oprimidos. Não obstante, os militantes percebiam que a maioria desses levantes e do apoio que estavam levando ainda eram dos seus próprios conterrâneos. Eles conseguiram dialogar com a classe trabalhadora e com os marginalizados dos bairros operários que circulavam na cidade, mas parecia que essa solidariedade era mais forte entre imigrantes como eles, especialmente os próprios italianos, das suas mais variadas

28 Sobre a estratégia organizacionista, cf. SAMIS. "Minha pátria é o mundo inteiro.", p. 95.

29 Para um estudo profundo sobre os grupos de afinidade anarquista, cf. TOLEDO, Edilene. "Amigo do Povo: grupos de afinidade e a propaganda anarquista em São Paulo nos primeiros anos deste século." (Dissertação de mestrado em História, Universidade Estadual de Campinas, 1994).

30 Para adentrar as diferenças entre o antiorganizacionismo brasileiro e de outros grupos no mundo, cf. SCHMIDHT; VAN DER WALT. Black Flame, p. 128-132.

31 BIONDI. "La stampa anarchica in Brasile", p. 70-76.

32 Cf. SAMIS. "Minha pátria é o mundo inteiro.", p. 95.

33 LEAL, Claudia Baeta. "Anarquismo em verso e prosa: literatura e propaganda anarquista na imprensa libertária em São Paulo (1900-1916)". (Dissertação de mestrado em História, Universidade Estadual de Campinas, 1999), p. 30-82. 
regiões. ${ }^{34}$ Acreditando numa ajuda mútua internacional como liam nos clássicos anarquistas, tais militantes, como Bandoni, procuraram o possível motivo dessa apatia entre os oprimidos e trabalhadores brasileiros e ao tentar comparar, por vezes, os processos reivindicatórios dos lugares de origem ou das fábricas e fazendas de maioria étnica italiana, anexavam discursos de segregação, julgando a população nativa como passiva, assim como a rede política institucional do Brasil como atrofiada ou retrógrada:

Deixamos de lado o proletariado nacional, este está ainda em formação e com ele ninguém pode contar. É um rebanho de eleitores a bom preço. Falta a preparação histórica, talvez também o próprio ambiente econômico com o qual possa se formar um proletariado indígena. Temos bons companheiros brasileiros, operários ou profissionais, mas, por favor, não vamos procurar o socialismo, o sindicalismo e o anarquismo nas sociedades indígenas, organizadas com fins políticos, de vulgar política. 35

É necessário ainda salientar que, mesmo marcadas por essa tendência, as associações étnicas não eram uma particularidade do movimento anarquista. Para historiadores como Luigi Biondi e Michael Hall, as sociedades de socorro mútuo, ligas sindicais e grupos políticos comumente se associavam com membros que se reconheciam por locais de origem ou língua comum. Alguns bairros e regiões tinham uma presença marcante e até esmagadoramente majoritária de imigrantes. Estes, por sua vez, se viam isolados, juntamente com boa parte da população, da política institucional brasileira, resultando no florescimento de uma ligação imaginária étnica e, nesse sentido, tal tendência facilitava os processos de organização política e sindical, em um primeiro momento. De fato, em outros casos, esse ideário pode ter emperrado movimentos de resistência mais amplos, levando em conta a heterogeneidade do composto dos trabalhadores em outras regiões. No entanto, tal caráter, como mostram os pesquisadores, na prática, não necessariamente excluía outros tipos associações, como de ofício, contando com uma forte resistência classista. ${ }^{36}$

Os próprios personagens ligados ao La Battaglia, como Angelo Bandoni, que estamos acompanhando, apresentavam também uma clara posição de classe, refletindo o próprio ambiente no qual se desenvolviam. Eles afirmavam:

Essa classe média nunca experimentou a pobreza, a conhece apenas por um quadro deixado para trás como eles escreveram; para apenas falarem sobre isso, se sentem atacados por emoções de horror. Fiéis ao seu gordo salário, se apresentam a partir de lições presas aos jornais

34 Para examinar as particularidades do grupo La Battaglia, cf. BIONDI, Luigi. "Anarquistas italianos em São Paulo. O grupo do jornal anarquista "La Battaglia" e a sua visão da sociedade brasileira: o embate entre imaginários libertários e etnocêntricos". Cadernos Arquivo Edgard Leuenroth, Campinas, v. 5, n. 8/9, p. 117-148, 1998.

35 La Battaglia, São Paulo, 31 jul. 1912, p. 2. Citado e traduzido por BIONDI. "Anarquistas italianos em São Paulo", p. 143. Citação original: "Lasciamo da parte il proletariato nazionale, questo è ancora in formazione e con essa nessuno può dire. Si tratta di uno stormo di elettori ad un buon prezzo. Mancano la preparazione storica, forse l'ambiente molto economica con cui formare un proletariato indigena. Abbiamo buoni colleghi brasiliani o professionisti, ma per favore, cerchiamo di non guardare per il socialismo, il sindacalismo e I'anarchismo nelle società indigene, organizzata a fini politici, la politica volgare."

36 Para adentrar os estudos que estudam os embates entre posições classistas e étnicas no operariado em São Paulo, cf. BIONDI, Luigi. Classe e Nação: trabalhadores e socialistas italianos em São Paulo, 1890-1920. Campinas: Editora da Unicamp, 2011; HALL, Michael. "Entre a Etnicidade e a Classe em São Paulo." In: CARNEIRO, Maria Luiza Tucci; CROCI, Frederico; FRANZINA, Emilio. História do Trabalho e Histórias da Imigração: Trabalhadores Italianos e Sindicatos no Brasil (Séculos XIX e XX). São Paulo: Editora da USP/ Fapesp, 2010, p. 49-64. 
conservadores contratados, discutem política, mas limitando-se apenas a alegações de defeitos de ministros e alguns diplomatas, mas sempre dizendo bem do trabalho do governo. Ai, se você falar com eles de ideias progressistas, do socialismo, da anarquia!37

Apresentando um ideário étnico particular, outro filtro de agregação passava pela posição das classes sociais e, portanto, dos seus próprios embates. Ao recusar a junção dos seus interesses com as classes mais abastadas, os ativistas em torno do grupo revelavam o seu próprio lugar e também seus objetivos. Assim, apesar dessa imaginação étnica, Bandoni e seus associados, ao militarem junto a outros grupos e com suas posições de classe, garantiam sua proximidade com a população dos bairros operários e com os trabalhadores nas fazendas em geral.

Nos próximos anos, as práticas que acompanhavam os diversos grupos anarquistas começavam a influenciar e acompanhar o próprio desenvolvimento do movimento operário na cidade. Muitos desses ativistas, mesmo divergindo em seus discursos e algumas práticas sobre a posição do sindicalismo e seus usos, atuavam, com suas respectivas posturas, em importantes organismos trabalhistas. Esse caráter foi demonstrado na construção da Confederação Operária Brasileira ( $\mathrm{COB}$ ), iniciativa altercada no Primeiro Congresso Operário Nacional, principalmente pela experiência das associações sindicais do Rio de Janeiro, entre eles a Federação Operária do Rio de Janeiro (FORJ), herdeira da Federação Operária Regional. A COB, com limitações para se constituir nacionalmente, se esforçava para coordenar e ligar as associações trabalhistas de várias regiões do Brasil, como São Paulo, Distrito Federal, Rio Grande do Sul, Ceará e Pernambuco, e de diferentes orientações e funções, como as de ofício ou pluriprofissionais. ${ }^{38}$

Os antiorganizacionistas anarquistas, ainda céticos em relação às entidades sindicais, acompanharam as decisões e caminhos tomados, do contrário não seria possível a formulação de duras críticas encontradas no La Battaglia sobre o referido congresso, especialmente sobre a escolha do sindicalismo revolucionário. ${ }^{39}$ Consequentemente, os aderentes dessa estratégia deixavam seus rastros, mesmo minoritários, e igualmente absorviam práticas e intenções para sua bagagem militante. Como o historiador Carlo Romani nos mostra, nesse período, Oreste Ristori e seus aliados, como Bandoni, também participavam da própria construção

37 La Battaglia, São Paulo, 22 abr. 1908. p.2. Tradução nossa. Citação original: "Questa classe media non hai provato l'indigenza, e concoscendola solamente per un quadro sinistro, dietro a quanto se ne scrive, al solo parlarne, si sente assalita da un brividio di orrore; fedele al suo pingue salario, s'attegia a conservatrice e, prendendo lezione dai giornale prezzolati, discute di politica, limitandosi a censurare i defeti dei ministri e di qualche diplomatico, ma dicendo sempre bene dell'operato del Governo. Guai se parlate ad essa di idee progressive, di socialismo, di anarchia!"

38 Cf. TOLEDO, Edilene. "Para a união do proletariado: a Confederação Operária Brasileiro, o sindicalismo e a defesa da autonomia dos trabalhadores no Brasil na Primeira República." Perseu: história, memória e política, São Paulo, n. 10, v. 7, p. 11-32, dez. 2013.

39 Para Alexandre Samis, o sindicalismo revolucionário defendia "a neutralidade sindical, federalismo, antimilitarismo, antinacionalismo, greve geral, boicote, sabotagem" além de instruir a não vinculação de nenhuma vinculação ideológica, inclusive o anarquismo, nesses ambientes, favorecendo a luta material dos trabalhadores. Para alguns autores, como esse e Tiago Oliveira, embora as entidades sindicais como a COB tivessem representantes não anarquistas, a escolha dessa estratégia revela uma articulação política libertária no interior desses organismos. Para outros, como Edilene Toledo e Fernando Teixeira da Silva, alguns personagens revogaram a ideologia anarquista nessa estratégia transformando-a, em vários pontos do globo, numa ideologia autônoma em relação ao anarquismo e socialismo. Para adentrar o debate ver SAMIS. "Minha pátria é o mundo inteiro", p. 114; OLIVEIRA, Tiago Bernardon de. "Anarquismo, sindicatos e Revolução no Brasil (1906-1936)" (Tese de doutorado em História, Universidade Federal Fluminense, 2009); TOLEDO, Edilene. Travessias revolucionárias: ideias e militantes sindicalistas em São Paulo e na Itália (1890-1945). Campinas: Editora da Unicamp, 2004; SILVA, Fernando Teixeira da. "Operários sem patrões: da Barcelona à Moscou brasileira (trabalho e movimento operário em Santos no entreguerras" (Tese de doutorado em História, Universidade Estadual de Campinas, 2000). 
do movimento operário ao não se oporem "sistematicamente às greves parciais enquanto forma de luta de uma ou mais categorias. Em muitos casos, além de abrir[em] espaço a cada edição, para o acompanhamento dos movimentos grevistas em andamento, envolvia[m]-se diretamente em sua articulação e difusão". 40

Os mesmos encaminhamentos, que englobavam diversos projetos, mas que revelavam a presença dos anarquistas, deram-se na constituição da primeira tentativa de construção da Federação Operária de São Paulo (FOSP) em 1905. Essas práticas possibilitaram uma junção com os eventos reivindicatórios, como as greves incitadas nas comemorações do primeiro de maio em 1907. Naquela data, a partir do dia 4 de maio, os metalúrgicos da Companhia Lidgerwood, ao protestarem por melhores condições e a jornada de oito horas, foram conectados por outras categorias como pedreiros, sapateiros, tecelões, gráficos, possibilitando considerável amplitude reivindicativa. Os anarquistas, sobre uma meta internacional, encaminhavam sistematicamente as lutas pelo direito às oito horas de trabalho. Esses, além de sua posição no interior da FOSP, ofereceram discussões e disseminaram notícias por meio de diversos jornais, entre eles o Germinal, La Battaglia, que tinham a participação incisiva de Bandoni. Algumas categorias saíram vitoriosas, pelo menos durante algum tempo em que vigoraram os diretos requeridos. ${ }^{41}$

A repressão policial, como era comum sobre os grupos ativistas, caiu sobre a FOSP, dissolvendo o organismo e prendendo alguns de seus militantes. Angelo Bandoni continuava a discursar nos bairros operários e a escrever nos jornais em que participava, incentivando a população não esmorecer diante de tais atos. Não obstante, com o crescimento das atividades sindicais, greves e boicotes, os chefes industriais cobravam medidas enérgicas do aparelho estatal. A mencionada repressão teve alguns amparos legais em 1907 criados pelo Congresso, ao visualizar o potencial perigo das agitações para o projeto republicano, sancionadas pelo então presidente Rodrigues Alves:

O primeiro obrigava os sindicatos a depositarem seus estatutos em cartórios, acompanhados da lista de nomes dos membros da diretoria. Por ele, ficava proibida a participação sindical de estrangeiros que não tivessem, pelo menos, cinco anos de residência no país. O segundo, também conhecido como Lei Adolfo Gordo, regularizava a expulsão dos estrangeiros residentes no Brasil que, por qualquer motivo, comprometessem a segurança nacional ou a tranquilidade pública. ${ }^{42}$

A partir de 1912, depois da eleição do militar Hermes da Fonseca dois anos antes e de outras articulações políticas dos grupos conservadores, as leis para a permanência de estrangeiros no país também ficaram mais rígidas, assim como o aumento de tentativas de expulsão. É difícil saber com precisão os efeitos dessas medidas e leis, já que a primeira, por exemplo, teve poucos efeitos sobre a militância mais assídua pois a maioria dos principais estrangeiros anarquistas nesse período estavam no país desde o começo do século. É necessário salientar, em todo caso, que em vários momentos atitudes arbitrárias das autoridades policiais eram colocadas em prática empastelando jornais ou entidades sindicais, principalmente

40 ROMANI. "Oreste Ristori." p. 153-154.

41 cf. LOPREATO, Christina. "O espírito da revolta: a greve geral anarquista de 1917." (Tese de doutorado em História, Universidade Estadual de Campinas, 1996), p. 12.

42 LEAL. "Anarquismo em verso e prosa", p. 52-53. 
quando paralisações e manifestações eram planejadas ou realizadas. ${ }^{43}$ Angelo Bandoni ao denunciar com frequência tais atos em suas falas e colunas presenciou e fugiu de muitas intentonas repressivas e violentas, bastante comuns em sua trajetória desde que foi considerado criminoso pelas autoridades, antes mesmo de se tornar um anarquista.

\section{"Guerra à Guerra": o momento de se tornar verdadeiramente brasileiro.}

No dia 12 de julho de 1913, vinha a iniciativa do grupo de Angelo Bandoni, junto de Gigi Damiani e Alessandro Cerchiai, para a publicação do jornal La Propaganda Libertaria. O jornal teve uma breve experiência de dois anos e sofreu diversas interrupções e dificuldades de se manter financeiramente, mostrando uma queda evidente de leitores em comparação com outros jornais nos quais o grupo estava envolvido, como - La Battaglia. Dessa vez, os personagens ligados ao periódico estavam sendo influenciados pelo contexto de grande repressão econômica do período e também pelo refluxo do movimento operário. De fato, posições da estratégia antiorganizionista e das táticas antissindicalistas estavam ainda presentes no grupo, mas abertos às possíveis críticas e discussões nesses ambientes, o referido grupo, pela própria condição emergente, tentava atuar em diversos organismos e círculos militantes, mesmo que assinalando suas considerações contundentes.

Em várias empreitadas, como na tentativa da reanimação da Confederação Operária Brasileira, que estava sendo enfraquecida devido a esses fatores e a mencionada repressão, era destacada sua atuação e associação com outros grupos como o Centro Socialista Internacional, que tentava reunir os diversos grupos anarquistas, incentivando movimentos classistas e internacionalistas. Buscando entender os motivos da apatia do movimento operário, Bandoni e seus companheiros buscavam nos eventos e debates socialistas, anarquistas e sindicalistas internacionais e locais motivos para mobilizar seus leitores:

Eis a grandiosidade do programa dos revolucionários mexicanos, que, ao fundo, é bem o programa dos anarquistas de todo o mundo! [...] Enquanto dezenas e dezenas de milhares de homens e mulheres põem em prática as ideias que animam a revolução, outras dezenas e dezenas de milhares de pessoas continuam a percorrer todos os cantos do México para propagar e proclamar bem alto os princípios de Terra e Liberdade para Todos!44

Além de tentar trazer eventos internacionais para a possível mobilização e ação dos militantes e dos trabalhadores na cidade, a propaganda também começou a ser dirigida contra os conflitos nacionais em outros países que, além de ocasionarem grandes danos às classes baixas, para os redatores como Bandoni, "o início das guerras dos estados balcânicos contra a Turquia" 45 marcaria o poder dos estados nacionais ligados aos detentores dos meios de produção já que esses últimos seriam "acionistas das grandes fábricas de armas e munições, bem como

43 Para um estudo aprofundado da repressão contra os anarquistas, cf. LEAL, Claudia. "Pensiero e Dinamite: Anarquismo e repressão em São Paulo nos anos de 1890" (Tese de doutorado em História, Universidade Estadual de Campinas, 2006).

44 La Propaganda Libertaria, São Paulo, 15 nov. 1913, p. 4. Trecho em português.

45 La Propaganda Libertaria, São Paulo, 12 jul. 1913, p. 2. Trecho em português. 
fornecedores dos exércitos e dinheiro."46

Com o avanço dos conflitos mundiais, incluindo a eclosão da Primeira Guerra Mundial, essa postura foi progressivamente levada a cabo pelos militantes anarquistas na cidade. Em 1915, Angelo Bandoni reformula suas táticas, lançando um novo jornal intitulado Guerra Sociale, conseguindo, desta vez, ter regularidade semanal ou quinzenal. O nome apostava incisivamente na propaganda contra os conflitos internacionais que estavam chamando a atenção dos mais variados grupos sociais.

Em setembro de 1916, um ano após o início das publicações do periódico Guerra Sociale, Bandoni apresentou uma chamada intitulada "Pela nossa guerra e pela nossa paz" 47 numa página anexa. A função da nota era sistematizar e reafirmar posições apresentadas durante a trajetória do jornal até aquele momento. Os militantes anarquistas, incluindo Bandoni, com o mote "Guerra à Guerra"48 mostravam que eram necessárias atitudes incisivas por parte dos trabalhadores e dos grupos subalternos contra os responsáveis pelos conflitos nacionais e suas consequências em âmbito global. Ao fazerem isso, explicavam que tais conflitos não eram uma "maldição de um deus maligno, agora cínico e feroz, mas de uma ordem social."49 Para os personagens envolvidos com o periódico, portanto, as evocações nacionalistas e militaristas provinham dos "interesses do capital: a rivalidade, o apetite dos diferentes grupos financeiros, o expansionismo colonial, o estatismo, o nacionalismo, todas as suas instituições e toda a sua moral, com base na violência." 50

Desse modo, interpretando que os embates de caráter nacionalista provinham dos projetos ligados aos grupos detentores dos meios de produção industrial, influenciando os rumos políticos, os envolvidos com a fundação do jornal, majoritariamente provindos das regiões italianas, começaram a tensionar a posição etnocêntrica que alguns militantes, anos antes, haviam apresentado. Sobre outra campanha, o jornal mostrava:

[...] nós vivemos sob uma parte da terra a que chamamos de Brasil, que possui um presidente, ministros, deputados, empregados e soldados. Pois bem, é vizinho dele um outro país chamado Argentina, que por sua vez também possui um presidente, ministros, deputados, empregados e soldados, é vizinho deste um outro chamado Chile, vizinho deste outro chamado Peru, etc., etc., que são partes componentes da América e do mundo - em todos estes países vivem homens formados igualmente a nós, com um nariz, uma boca, olhos e orelhas, homens que não nos conhecem e não nos querem fazer mal, e aos quais, por nossa vez, não desejamos mal..$^{51}$

Muito mais do que propagar apenas um suposto valor de igualdade, a forte retomada do internacionalismo, a partir de uma visão libertária e classista, resultou

46 La Propaganda Libertaria, São Paulo, 12 jul. 1913, p. 2. Tradução nossa. Citação original: "Nel principio della guerra degli stati baleanici contro la Turchia, mentre la camarilla borghese, azionista delle grandi fabbriche di armi e munizioni, nonchè fornitrice degli eserciti in campagna e di danaro [...]"

47 Guerra Sociale, São Paulo, 20 set. 1916. Anexo. Tradução nossa. Citação original: "Per la nostra guerra e per la nostra pace."

48 Guerra Sociale, São Paulo, 20 set. 1916. Anexo. Tradução nossa. Citação original: "Guerra alla guerra."

49 Guerra Sociale, São Paulo, 20 set. 1916. Anexo. Tradução nossa. Citação original: "[... ] maledizione di un dio malvagio, ora cinico e feroce, ma un ordine sociale[... ]."

50 Guerra Sociale, São Paulo, 20 set. 1916. Anexo. Tradução nossa. Citação original: "[...] agl'interessi del Capitale: le rivaltá, gli appetiti dei diversi aggruppamenti finanziari, l'espansionismo coloniale, lo statismo, il nazionalismo, tutte le sue istituzioni e tutta la sua morale."

51 Guerra Sociale, São Paulo, 1 maio 1916, p. 2. Trecho em português. 
também na busca de elementos históricos que poderiam comprovar os motivos dessas desigualdades entre grupos diferentes:

As aspirações que animaram os combatentes pela extinção da escravatura dos homens de cor foram grandes e generosas, mas, em realidade a maldita escravidão das massas proletárias ainda não foi abolida. Com efeito, os homens de cor continuam a ser considerados como escravos, como bestas. Hoje diz-se entre a gente burguesa 'quem escapou de branco é preto e preto não é gente'. O ódio da raça perdura em toda a sua intensidade, voltando-se aos homens de cor o mais profundo desprezo. E não somente os ex-negreiros, os padres e os funcionários públicos declaram que os homens de cor não têm espírito ou inteligência, mas até os pseudocientistas sustentam que a raça negra e a mestiça constituem espécies ou variedades incapazes de evoluir. Neste rol são também compreendidos os indígenas, habitantes dos sertões, os quais são vítimas da ferocidade dos negreiros nacionais ou estrangeiros, tipos sem entranhas, que com o auxílio dos capangas e das forças legais massacram essa pobre gente..$^{52}$

É interessante perceber que esses ativistas entendiam que as práticas e pensamentos racistas eram compartilhados por boa parte da população, destacando as classes médias e altas, mas que provinham de diversas esferas de dominação (econômico, social e ideológico), a partir de resquícios históricos e de discursos contemporâneos. Para uma atuação efetiva, porém, mostravam que, no momento, era necessária a destruição completa dos grupos ligados à economia vigente em consonância com os poderes estatais, pois além de reinterpretarem tais ideários para seus interesses, como era o caso dos conflitos nacionais, sublinhado pelo jornal, esses que eram culpados pela divisão da classe trabalhadora a partir de diferenças patrióticas.

Nesse período, a situação dos trabalhadores não era a mesma de anos atrás. Embora, como notado, boa parte da população nos centros industriais da cidade possuía suas raízes de nascimento no continente europeu, a vivência destes com os brasileiros ou com outros imigrantes se tornava mais comum com o passar dos anos. O contexto da Primeira Guerra Mundial que dificultava o fluxo da vinda de imigrantes para o país, assim como barrava a tentativa destes de retornar para sua terra natal, foi somado à grande migração das áreas rurais para o centro industrial, condições que resultaram o surgimento de um ideário de fixação que levava em consideração "construir uma vida em São Paulo sem pensar mais em voltar."53 Fato que, para alguns autores, como Sheldon Maram, significou, mesmo com a continuação da instabilidade na vida dos residentes dos bairros operários, se ater mais incisivamente à luta classista em sua região. ${ }^{54}$

É dentro dessa experiência e contexto que Angelo Bandoni, em torno do Guerra Sociale, mostrava sua intenção em aderir comportamentos que legitimassem sua ideologia e fossem eficazes para a população brasileira. Dessa forma, destacando a heterogeneidade étnica entre seus leitores e militantes e apelando para importância de sua união, o personagem também fazia questão de publicar colunas em língua portuguesa e espanhola. Dessa vez, para o historiador Tiago Bernardon de Oliveira, essa medida fazia parte de uma "batalha para a unificação do conjunto da classe, por cima das diferenças de cor, [que] constituíram uma

52 Guerra Sociale, São Paulo, 13 maio 1916, p. 3. Trecho em português.

53 BIONDI. Classe e Nação, p. 326.

54 Cf. MARAM, Sheldon. Anarquismo, imigrantes e o movimento operário brasileiro: 1890-1920. Rio de Janeiro: Paz e Terra, 1979. 
pedagogia pela qual se procurou enfrentar e superar as divisões sociais, junto com a superação do capitalismo pela classe trabalhadora." 55

Vislumbrando as atrocidades da guerra que estava presenciando e a apatia do movimento que ajudou a construir, Bandoni via que era o momento de colocar em prática aquele internacionalismo que tinha lido nos clássicos e ouvido falar nos círculos anarquistas, mas, ao mesmo tempo, se tornando um brasileiro. O mesmo publicou:

\begin{abstract}
Como é interessante tudo isso. Os governos contraem as dívidas? 0 povo que as pague! Os governantes declaram guerras? $O$ povo que morra! E quando for preciso, que se forneçam também ao governo soldados e policiais para que espingardeiem o povo no dia em que achar que tudo isso vai mal. [...] E entre os conselhos que damos ao povo, o primeiro é este: não se deixe arrastar por politiqueiros, que os mandarão à chacina, para que eles possam substituir no poder os atuais dominadores. [....] Reflita, porém, que num ou noutro caso, antes ou depois, ele deverá, por si ou por outros, vir à rua, revoltar-se e baterse pela defesa dos seus interesses ou daqueles que lhe farão crer que são os seus. Como hoje, no dia em que tiverem lugar acontecimentos graves, nós voltaremos a dizer que, em vista de a luta ser fatal, inevitavelmente, saiba o povo enfrentá-la por conta própria, a fim de conquistar para si a pátria brasileira, este rico pedaço do mundo que pode dar pão e felicidade a quantos não odeiam o trabalho. E nesse dia estaremos a seu lado. Ao lado dos politiqueiros e dos comerciantes é que nós, os anarquistas, nunca marcharemos. ${ }^{56}$
\end{abstract}

É revelador perceber como o próprio personagem mobilizava e instrumentalizava os imaginários nacionalistas para fazer frente ao antiimperialismo e aos conflitos nacionais. Ao sublinhar "pátria brasileira", o ativista reconhecia que, no momento, a evocação de uma ideia de pertencimento estava crescendo, já que estava no discurso de intelectuais e até mesmo das campanhas oficiais. Não obstante, ao destacar também que os reais ganhos dependiam das lutas "por conta própria", evocava e incentivava a luta unida da nação, mas fora do ambiente parlamentar e do lado dos interesses das classes consideradas exploradas. O intuito, portanto, para Bandoni e seus associados, era usar uma ideia de nação para encorpar e garantir um embate efetivo, disputando tal nomenclatura e ideário. O sucesso da nação e a felicidade dos seus habitantes, nessa visão, não deveriam vir de rivalidades nacionais, mas de fazer frente, de forma unida, contra os supostos causadores dessas calamidades, os governantes, que também estavam ligados, nesse pensamento, a interesses econômicos e políticos. O internacionalismo e aquela solidariedade que pregava Bandoni e outros de seus amigos anarquistas só faria sentido se conseguissem unir o local onde moravam e sofriam.

Nesse viés, parecia, para Bandoni e muitos dos redatores de seu jornal, que a luta em grupos esparsos e não formais, que eram formados inclusive para se defenderem da repressão, não garantiria um ataque sistêmico aos poderes que queriam destruir. Era necessário uma união com os outros grupos anarquistas de forma organizada e coesa e aderirem, se for a decisão da maioria, às suas táticas. Se opondo às tendências individualistas, e buscando meios práticos entre os grupos, ou na palavra dos próprios redatores, "um sentido", Bandoni e seu grupo

55 OLIVEIRA. "Anarquismo, sindicatos e revolução no Brasil", p. 245-246.

56 Guerra Sociale, São Paulo, 27 jan. 1917, p. 1. Trecho em português. 
propuseram a Aliança Anarquista, que era acompanhada de um manifesto contendo seus objetivos:

A Aliança fomentará, por todos os meios ao seu alcance, a propaganda contra as causas fundamentais da conflagração atual e de todos os males sociais que têm como origem o Estado e a propriedade individual, de instituições particulares e públicas [....] A Aliança combaterá a propaganda eleitoral e qualquer partido político estatal, mesmo o que se propunha reformar e, por tanto, consolidar a atual organização política e econômica, ou qualquer outra que se assenta sobre as aberrações nacionalistas e patrióticas. [...] Com relação ao movimento de classe, a Aliança favorecerá o desenvolvimento das organizações econômicas de resistência dos operários das cidades e dos trabalhadores rurais ou colonos, provocando-as, mesmo, onde não existam, elaborando, para este fim, um programa especial, subordinado, porém, a sua intervenção e ação à propaganda integral do anarquismo. ${ }^{57}$

AAliança Anarquista, portanto, apostava em uma forma dupla de organização. De um lado, visava a luta gradual pela melhoria material dos grupos trabalhistas ou subalternos, adentrando e impulsionando os movimentos destes, desde que dentro do espectro internacionalista e classista e fora da esfera parlamentar ou estatal. E, ao mesmo tempo, defendia a própria organização dos anarquistas a partir de bases internas, definindo métodos para suas atuações nos respectivos ambientes essencialmente econômicos, transformando esses, ocasionalmente, em instrumentos também de reclamação política, por meio de insurreições. Bandoni e seu grupo, agora, seguiam a estratégia organizacionista e se tornavam assíduos nos ambientes sindicalistas que criticavam anteriormente.

Desde março de 1917, esse grupo, por meio da Aliança Anarquista, que teve adesões em toda a cidade e até em outros pontos do país, impulsionava, junto ao grupo redator do periódico A Plebe,,$^{58}$ o Comitê Popular de Agitação Contra a Exploração de Crianças, lançando um manifesto incisivo sobre as condições de trabalho destas nas fábricas e requerendo a proibição dessa prática pelos empregadores. O projeto veio do êxito extraído de um debate político dos militantes para ser usado e construído também pela própria classe operária e subalterna:

O êxito da agitação que contra a exploração de menores vem desenvolvendo-se está superando a expectativa dos seus iniciadores. O entusiasmo que este protesto desperta entre o povo aumenta dia a dia, e, a cada momento, chegam novas adesões de entidades populares ou de pessoas que se apresentam dispostas a prestarem seu concurso material e moral. Por sua vez, o Comitê Popular de Agitação, coerente com o caráter da sua constituição e dos fins que se tem em vista, procurou que este movimento, genuinamente popular, não fosse desvirtuado pelos interesses de qualquer partido, ou por especulações mais ou menos políticas e legalitárias, tendentes a prestigiar os profissionais da exploração eleitoral. Nesse sentido, o Comitê elaborou um programa de ação exclusivamente popular e direta, o qual em numerosa assembleia de delegados das entidades aderentes foi aprovado com entusiasmo. Delegados de várias associações, apesar da diversidade de princípios que as separam, manifestaram-se justificando a sua aprovação do

57 Guerra Sociale, São Paulo, 14 out. 1916, p. 3. Trecho em português.

58 Para acompanhar a construção do jornal A Plebe e sua posição na greve geral de 1917, cf. SANTOS, Kauan. "Derrubando fronteiras: a construção do jornal A Plebe e o internacionalismo operário em São Paulo (19171920)". História e Cultura, Franca, v. 4, n. 1, p. 116-130, mar. 2015. 
programa apresentado pelo Comitê.59

Foi com essas articulações que Angelo Bandoni conseguiu sua presença na greve geral de 1917, quando, na semana de nove a dezesseis de julho, paralisações de diversas categorias e regiões de São Paulo, acompanhadas de intensas manifestações revelavam uma intensidade inédita, se alastrando posteriormente para cidades do interior paulista e outras regiões como o Rio de Janeiro e o Rio Grande do Sul.60

Para muitos trabalhadores do período, a greve geral foi vencedora já que saiu com promessas de industriais e governantes, como o prefeito Washington Luís, que garantiram a melhoria das relações de trabalho com a promessa de fazer cumprir as leis para regulamentação das atividades de mulheres e crianças em todos os estabelecimentos. Muitos industriais também concederam aumento de salário e alguns passaram a estabelecer, por algum tempo, oito horas de trabalho como plano da jornada de atividades. Tudo isso foi mediado e redigido pela Comissão de Imprensa, na qual participavam vários jornais da grande mídia, cobrindo tais promessas e exigências, o que deixava muitos da população com uma sensação de vitória. ${ }^{61}$

Entretanto, para os militantes libertários, os ganhos só valeriam se a luta se estendesse para uma ruptura contra o sistema então vigente. Angelo Bandoni continuava, em suas palestras, mostrando que embora as promessas do Estado e dos representantes das fábricas fossem cumpridas, não demoraria muito tempo para que alguns locais voltassem a exercer o trabalho exploratório de mulheres e crianças e aumentassem novamente a jornada de trabalho, condições que só acabariam definitivamente com uma revolução proletária a partir da reunião novamente das forças operárias e dos oprimidos, assim como das coligações militantes, deixando as diferenças de lado, quando fosse necessário. ${ }^{62}$ Depois da greve geral de 1917, uma repressão intensa se inclinou contra os anarquistas e sindicalistas, mas eles teriam ainda outros problemas e embates pela frente.

\section{Considerações finais: por onde andou Angelo Bandoni?}

No dia 26 de janeiro de 1919 é lançado, na capital paulista, o primeiro número do periódico Alba Rossa, dirigido por Angelo Bandoni. Após a intensa repressão desencadeada com a onda grevista de 1917 e a desintegração de uma aliança pela necessidade de impulsionar os órgãos sindicais, alguns anarquistas interpretaram ser necessário voltarem para suas táticas propagandísticas, restaurando suas atividades em grupos móveis no intuito de tentarem uma proteção dos ataques provindos das autoridades e também da disputa mais intensa nos sindicatos pelos comunistas, organizados em partido a partir de 1922. No início da terceira década do século passado, Angelo Bandoni continuou sua militância assiduamente como propagandista, educador e palestrante, sendo um dos primeiros anarquistas a realizar críticas ao endurecimento do regime socialista

59 Guerra Sociale, São Paulo, 12 mar. 1917, p. 1.

60 Para um estudo aprofundado da greve geral de 1917, cf. LOPREATO. "O espírito da revolta."

61 LOPREATO. "O espírito da revolta", p. 127-228.

62 Para acompanhar as chamadas e os temas das palestras de Angelo Bandoni ver os periódicos Guerra Sociale e A Plebe no ano de 1917. 
na Rússia, após a maioria dos libertários do país apoiarem o evento e trazê-lo como propaganda para suas ações grevistas e reivindicativas. Com o avanço do fascismo na Europa danificando o sindicalismo revolucionário e do golpe de Getúlio Vargas rearranjando o movimento operário no Brasil, o militante continuou suas ações em outros espaços, participou de importantes frentes antifascistas como no jornal $L a$ Difesa, resistindo, assim como sempre fez, às tentativas de ordem que almejavam conservar as desigualdades. ${ }^{63}$

Não sabemos até onde essa difícil resistência durou, também não temos nenhuma informação se Angelo Bandoni foi deportado, como seu amigo Oreste Ristori que posteriormente foi fuzilado pelo regime de Mussolini na Itália, ou se foi um prisioneiro político em Clevelândia, no norte brasileiro, para onde militantes anarquistas e sindicalistas foram levados no regime de Arthur Bernardes. ${ }^{64} \mathrm{O}$ militante também não parece se reorganizar na década de 1950, quando alguns anarquistas antigos se reuniram novamente. ${ }^{65}$

Não obstante, Angelo Bandoni não precisa ser um mártir nem mesmo um herói incorruptível para aprendermos com sua trajetória nessas décadas que nos atemos. O militante, embora importante no movimento político que fez parte e até mesmo no plano mais geral do próprio movimento operário e nas reivindicações subalternas, nunca se proclamou um líder e muitas vezes, como vimos, queria que a própria população se revoltasse a partir de suas próprias opressões, de suas vivências. Assim como ele acreditava, não pretendemos mostrar sua trajetória política como um exemplo ou como a personificação do movimento anarquista ou operário na Primeira República. Também não temos a ilusão que esse personagem era um trabalhador ou homem "comum", ou seja, o típico, já que ele sabia ler, escrever, havia tido contato e ajudou a construir uma ideologia e corrente política, coisa que a maioria dos trabalhadores e a classe subalterna não poderiam.

Não obstante, Angelo Bandoni tem um pouco de várias coisas, eloquente anarquista, mas também apenas um dos muitos criminosos e gatunos, antiorganizador e insurrecionalista, mas também observador e organizador, um "excepcional normal", ${ }^{66}$ na concepção de Carlo Ginzburg e Carlo Poni; que através dele, podemos enxergar "um ângulo de visão a partir do qual torna-se possível revelar dimensões de problemas maiores", ${ }^{67}$ ainda nas palavras do historiador Benito Schmidt.

Assim, o estudo de sua trajetória revelou que as conexões entre anarquismo, movimento operário, trabalhadores subalternos, transnacionalismo e anti-imperialismo são mais complexas do que visto anteriormente ou mesmo como foram enxergadas por sua família política. Nesse sentido, mesmo que o anarquismo tenha nascido entre os dilemas da classe trabalhadora, os problemas

63 Para um estudo aprofundado sobre o fascismo, o governo de Getúlio Vargas e perseguição política bem como a atuação de anarquistas nesse período, cf. ROMANI, Carlo. "Italianos, antifascismo e perseguição política na Era Vargas (1930-1937).” In: GONÇALVES, Leandro; SILVA, Érica Sarmiento da; VIANNA, Marly. Presos políticos e perseguidos estrangeiros na Era Vargas. Rio de Janeiro: Mauad X, 2014, p. 89-100.

64 Ver SAMIS, Alexandre. Clevelândia: Anarquismo, sindicalismo e repressão política no Brasil. São Paulo: Imaginário, 2002.

65 Sobre a reorganização do anarquismo, cf. SILVA, Rafael Viana da. "Indeléveis refratários: as estratégias políticas anarquistas e o sindicalismo revolucionário no Rio de Janeiro em tempos de redemocratização (1946-1954)". (Monografia de conclusão de curso, Universidade Federal do Rio de Janeiro, 2011).

66 O termo usado por Carlo Ginzburg e Carlo Poni refere-se ao personagem que é aparentemente excepcional, mas que se constituía a partir de práticas comuns ou verossímeis no cotidiano social. Cf. GINZBURG, Carlo; PONI, Carlo. "O nome e o como: troca desigual e mercado historiográfico". In: GINZBURG, Carlo. A microhistória e outros ensaios. Lisboa: Difel; Rio de Janeiro: Bertrand Brasil, 1989, p. 169-178.

67 SCHMIDT, Benito Bisso. "Trajetórias e vivências: as biografias na história do movimento operário brasileiro.” Projeto História, São Paulo, v. 16, n. 1, p. 233-244, fev. 1998. 
encontrados entre os trabalhadores subalternos fizeram com que os personagens adaptassem essa ideologia entre seus interesses fazendo circular e se desenvolver um anarquismo insurrecionalista e antiorganizador. Também podemos evidenciar a complexidade entre o internacionalismo anarquista e o transnacionalismo ou nacionalismo, uma vez que ideias anarquistas eram chocadas com ideários étnicos e de classe na cidade de São Paulo, resultando num tipo de prática militante bem particular.

No entanto, essas práticas, ideários e estratégias não podem se desenvolver longe de uma realidade e, por isso, foram revistas e mudadas em momentos emergenciais pelos seus militantes, como no caso da Primeira Guerra Mundial, ou diante de um refluxo dos movimentos reivindicativos. Uma mudança de paradigma no movimento libertário, almejando densidade nacional (mais um elo entre internacionalismo, classismo e nacionalismo) ganhou força graças à união de diversos personagens em torno de problemas comuns. Aqueles que mesclaram suas peculiaridades com dimensões maiores e transitam em meio aos variados contextos sociais, políticos e culturais reinterpretando tradições com necessidades e experiências maiores podem revelar essas vontades e assim foi com Angelo Bandoni. ${ }^{68}$

Recebido em 09/07/2016

Aprovado em 30/12/2016

68 Para Mike Savage "no lugar de inquirir quem é o mais importante, se é o local, se é o nacional, no caso de suas respectivas importâncias poderem ser pesadas e medidas, é melhor examinar não só as complexas interligações entre níveis espaciais distintos, mas também como mediadores espaciais - pessoas capazes de se moverem entre as escalas espaciais - podem vir a ter um papel-chave na geração de formas de mobilização política." SAVAGE. "Classe e História do Trabalho", p. 48. 